\title{
Detection of anti-avian bornavirus antibodies in parrots in the Czech Republic and Slovakia
}

\author{
Martina Vondráčková ${ }^{1}$, Viktor Tukačํ․ Veronika Grymová ${ }^{2}$, Pavlína Hájková3, \\ Zdeněk Knotek ${ }^{1}$, Gerry M. Dorrestein ${ }^{4}$
}

\author{
University of Veterinary and Pharmaceutical Sciences, Faculty of Veterinary Medicine, \\ Avian and Exotic Animal Clinic, Brno, Czech Republic \\ ${ }^{2}$ Avetum Veterinary Clinic, Brno-Mokrá Hora, Czech Republic \\ ${ }^{3}$ Avian Clinic, Praha, Czech Republic \\ ${ }^{4}$ Pathology Laboratory NOIVBD, Veldhoven, The Netherlands
}

Received March 10, 2014

Accepted May 28, 2014

\begin{abstract}
Since the avian bornavirus (ABV) aetiology of the proventricular dilatation disease (PDD) was proven in 2008, ABV has been detected in many avian species. The aim of the present study was to detect ABV antibodies in parrots in the Czech Republic and Slovakia. A total of 142 birds were examined, including 37 birds with symptoms typical for PDD, 54 birds without PDD symptoms, and 51 parrots without any clinical symptoms of PDD but originating from one flock with a proven history of PDD. Sera from 142 birds were tested using the enzyme-linked immunosorbent assay (ELISA) for detection of antibodies against ABV nucleoprotein p40. Of 142 serum samples, 71 were positive $(50 \%)$ and 71 negative $(50 \%)$. In a group of birds with clinical symptoms of PDD, $77.1 \%$ showed to be ABV positive, whereas in the group of sick birds without suspicion of PDD the percentage of positive birds was $31.6 \%$. In the birds that had a cage mate that was positive for $\mathrm{ABV}$ or died with PDD, $42.9 \%$ were ABV positive. Of the parrots without PDD symptoms but originating from the flock with a recent history of PDD, $62.8 \%$ of the birds were positive for antibodies against ABV nucleoprotein $\mathrm{p} 40$. The results suggest that PDD is common and there is a high percentage of asymptomatic carriers of $\mathrm{ABV}$ in the breeding facilities of parrots in the Czech Republic and Slovakia.
\end{abstract}

Birds, Psittaciformes, ELISA, nucleoprotein P40, proventricular dilatation syndrome

Proventricular dilatation disease (PDD, synonyms: proventricular dilatation syndrome, macaw wasting disease, neuropathic gastric dilatation of Psittaciformes, psittacine encephalomyelitis, myenteric ganglioneuritis, infiltrative splanchnic neuropathy) (Shivaprasad et al. 2010) is a common fatal disease in Psittaciformes. The disease was first noticed in the 1970s in a case of macaws imported to the United States from Bolivia (Clark 1984). Since then, PDD has been diagnosed worldwide (Hoppes et al. 2013). It has been described in more than 70 psittacine species including macaws (Ara sp.), hyacinth macaws (Anodorhynchus hyacinthinus), African grey parrots (Psittacus erithacus), cockatoos (Cacatua sp.), Amazon parrots (Amazona sp.), conures (Aratinga sp.), cockatiels (Nymphicu shollandicus), and some others. The disease has also been reported in various non-psittacine species kept in captivity: canaries (Serinus canaria), greenfinches (Carduelis chloris), long-wattled umbrella birds (Cephalopterus panduliger), Canada geese (Branta canadensis), roseate spoonbills (Ajaja spp.), toucans (Ramphastos spp.), bearded barbets (Lybius dubius) and in birds of prey (Falco peregrines) (Shivaprasad et al. 2010). Interestingly, PDD has not yet been described in budgerigars (Melopsittacus undulatus) or other small psittacines. Characteristically, PDD affects the neural tissues of the nervous and gastrointestinal systems. Lymphoplasmacytic infiltration in the nerves and ganglia of the peripheral and central nervous system is typical. This infiltration which is suggested

Address for correspondence:

Prof. MVDr. Zdeněk Knotek, CSc. Dip ECZM (herpetology)

Avian and Exotic Animal Clinic, Faculty of Veterinary Medicine

University of Veterinary and Pharmaceutical Sciences Brno

Palackého tř. 1/3, 61242 Brno, Czech Republic 
to be the result of production of gangliosides as an autoimmune reaction (Rossi et al. 2011) leads to behavioural abnormalities such as ataxia, abnormal gait, and proprioceptive defects. Common symptoms are also gastrointestinal dysfunctions such as dilatation of the proventriculus/gizzard, functional obstruction of the gizzard, dysphagia, regurgitation and the passage of undigested food in faeces (Gregory et al. 1994). These clinical symptoms may occur alone or in various combinations.

Until recently, the diagnosis of PDD was based on clinical symptoms, x-rays, crop biopsy and/or necropsy (Greg ory et al. 1994). Many viruses were considered as a causative agent, e.g. avian herpesviruses, polyomavirus, equine encephalitis virus, adeno-like viruses, coronaviruses, enteroviruses, and avian encephalitis virus. Especially, paramyxovirus was for a long time considered the most likely causative agent of PDD (Deb et al. 2008). However, none of these possible agents of the disease have been confirmed. In 2008, the avian bornavirus (ABV) was discovered as the causative agent of PDD and is now considered to be the agent involved. Avian bornavirus was found in birds affected by PDD (Honkavuori et al. 2008; Kistler et al. 2008) and after experimental inoculation with avian bornavirus-genotype 4 (ABV4) in cockatiels (Nymphicus hollandicus), patients developed lesions typical of PDD. This confirmed the relationship between avian bornavirus and PDD (Gancz et al. 2009). Recently, several infection trials have confirmed this relationship (Gray et al. 2010; Kistler et al. 2010; Piepenbring et al. 2012). Avian bornavirus is a negative strand, non-segmented RNA virus from the family Bornaviridae, and has been found in many avian tissues (Rinder et al. 2009), faeces, choanal and cloacal swabs. Transmission of the virus is most likely by faecal-oro-nasal routes (Kistler et al. 2010). Laboratory diagnosis of ABV is based on Western blot analysis to demonstrate ABV-specific antigens in tissues (Villanueva et al. 2010); indirect immunofluorescence assay (Herzog et al. 2010), and enzyme-linked immunosorbent assays (ELISA) to detect antibodies against ABV nucleoproteins (P40, P27, P24, P16 and P10) in bird sera (de Kloet and Dorrestein 2009); or RT/Realtime-PCR for detection of the broad spectrum of ABV genotypic variants (at least 7 in psittacines so far) in many types of clinical samples and necropsy materials (Honkavuori et al. 2008; Kistler et al. 2008; Dorrestein et al. 2009).

\section{Materials and Methods}

\section{Samples}

Serum was collected from 142 birds. Ninety-one (91) serum samples came from 64 different breeders and private owners in the Czech Republic and Slovakia. The remaining 51 samples came from one breeder. The species represented were Amazona sp. (62), Ara sp. (29), Psittacuserithacus (20), 12 cockatoos and low numbers of other parrot species. Of the 91 samples, 35 sera were collected from patients clinically suspected of PDD, and 2 sera were collected at necropsy with the macroscopic diagnosis of PDD. The other 54 birds were without typical symptoms of PDD, including 2 samples collected at necropsy. The mentioned 51 samples were collected as a part of an overall screening of clinically healthy birds in a breeding flock after a previous diagnosis of PDD in one dead bird at necropsy. The history of birds was divided into eight cohorts: 1a) patients with suspected PDD based on clinical examination; 1b) sick birds not suspected of PDD based on clinical examination; 2a) cage mates of ABV positive birds, not clinically ill; $2 b$ ) birds from collections of birds with PDD positive birds; 3 ) new birds health check or companion birds at home; 4 ) young birds (<1 year); 5a) dead bird with the typical pathology of PDD at necropsy; 5b) dead bird with no indication of PDD at necropsy.

\section{ELISA test}

Sera were tested using enzyme-linked immunosorbent assays (ELISA) for the detection of antibodies against ABV nucleoprotein P40. ELISA test was performed with minor modifications according to the methods described by de Kloet and Dorrestein (2009). After dilution, maltose-binding protein (MBP) and nucleoprotein P40 were applied to the wells of a medium binding polystyrene ELISA plate and incubated with shaking at room temperature for $1 \mathrm{~h}$. After $1 \mathrm{~h}$ the wells were washed with phosphate-buffered saline containing $0.05 \%$ Tween 20 (PBST). Then, non-fat dry milk in PBST was added and incubated at room temperature for $2 \mathrm{~h}$. Wells were washed again with PBST and incubated for $1 \mathrm{~h}$ at room temperature with $50 \mu \mathrm{l}$ of serum diluted in 5\% non-fat dry milk in PBST. Wells were again washed with PBST and incubated 
for an hour with $50 \mu \mathrm{l}$ of a 3,000-fold dilution of goat-anti-macaw-antibody labelled with AP (alkaline phosphatase) (Macaw IgG Antibody, Cat \# A140-116AP, Bethyl Laboratories Inc., Montgomery, TX, USA) in 5\% milk in PBST. After washing with PBST $50 \mu 1 \mathrm{pNPP}$ (para-Nitrophenyl-phosphate, P7998, SigmaAldrich Chemie, Zwijndrecht, The Netherlands), substrate was added and colour development was allowed for $30 \mathrm{~min}$ in the dark at room temperature $\left(20^{\circ} \mathrm{C}\right)$. Absorbance at $405 \mathrm{~nm}$ was read in a Multiskan FC ELISA reader (Thermo Scientific, Finland).

\section{Results}

Of 142 tested sera samples, 71 were positive $(50.0 \%)$ and 71 negative $(50.0 \%)$ for antiavian bornavirus antibodies. The results of 91 samples are shown in Fig. 1. Thirty-five (35) birds (cohort 1a) included in this group were suspected of PDD; the most common clinical signs were regurgitation, undigested food in faeces, progressive apathy and anorexia. Some birds showed also neurological signs such as opistotonus and tremor. The majority of suspected birds showed also a dilated proventriculus within radiography examination. Twenty-seven (27) birds in this group (77.1\%) were positive for antibodies against ABV nucleoprotein by ELISA. In a group of 19 sick birds without any symptoms of PDD (1b) 6 birds showed to be positive with ELISA assay (31.6\%). Of the birds that had a cage mate that was positive for ABV or died with PDD (2a), 3/7 birds (42.9\%) were infected with ABV. The birds tested in one suspected small flock $(2 \mathrm{~b}: 7)$ were all negative and individual birds that were recently purchased or kept as individual pet birds (3:7) were also all negative. Both necropsies with the diagnosis of PDD (5a) were ABV antibodies positive and the 2 birds that showed no signs of PDD (5b) at necropsy were free of antibodies against ABV. In the flock from where the 51 samples originated, 32 birds were positive with ELISA (62.8\%), 17 negative (33.3\%), and in 2 birds the results were aspecific $(3.9 \%)$. These results suggest a high percentage of asymptomatic carriers of ABV in this flock.

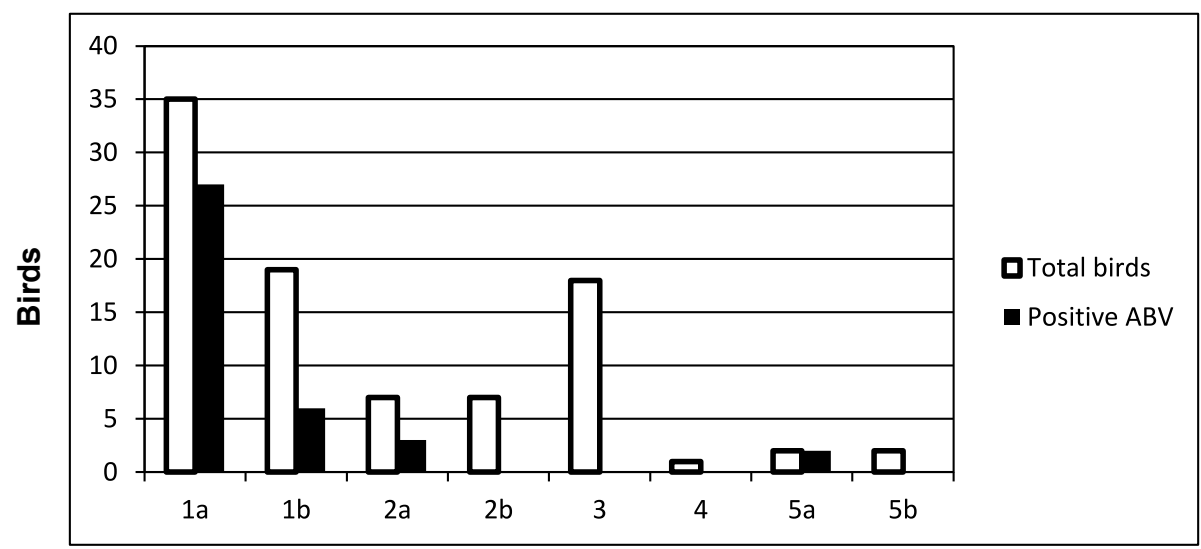

Groups

Fig. 1. Results of ELISA test for anti-avian bornavirus antibodies in birds with different histories of proventricular dilatation disease

1a - patients with suspected PDD based on clinical examination; $1 \mathrm{~b}$ - sick birds not suspected of PDD based on clinical examination; $2 \mathrm{a}$ - cage mates of ABV positive birds, not clinically ill; $2 \mathrm{~b}$ - birds from collections of birds with PDD positive birds; 3 - new birds health check or companion birds at home; 4 - young bird ( $<1$ year); 5a dead bird with the typical pathology of PDD at necropsy; 5b - dead bird with no indication of PDD at necropsy. 


\section{Discussion}

Proventricular dilatation disease (PDD) is a lethal avian disease, one of the most commonly seen in clinical practice with parrots. Results of the presented study showed a high percentage $(50 \%)$ of samples positive for the avian bornavirus antibody (p40) within the parrot species studied, with a very high percentage $(77.1 \%)$ of ABV positive birds in the group of parrots with typical clinical symptoms of PDD. This, like the results of previous studies that have been published, confirms the relationship between PDD and avian bornavirus. More than $20 \%$ negative results of ELISA in PDD suspected birds point out that a diagnosis of PDD cannot be based on the evaluation of clinical symptoms only. It is in accordance with the results of a similar study in the Netherlands and Belgium, where $58 \%$ of patients clinically suspected of PDD, $15 \%$ of patients without suspicion of PDD, and $50 \%$ of cage- or roommates of parrots have died of PDD. In that study $14 \%$ of healthy birds including retail birds were serologically positive for antibodies against ABV (Dorrestein et al. 2012). In that study including 3.294 serum samples, the agreement between the ELISA results and the results of ABV-RNA isolation from brain tissue, was 98\% for positive samples and $94 \%$ for negative samples (Dorrestein et al. 2012). From sera (or pericardial fluid) collected at necropsy from avian cadavers macroscopically suspected of PDD, 90\% were positive with ELISA assay, and those from cadavers without suspicion of PDD, 25\% were positive with ELISA assay. These results are comparable with our findings, showing that up to $14 \%$ of clinically healthy pet birds could be positive with ELISA assay. In the flock with a history of clinical cases of PDD we detected a high percentage $(62.8 \%)$ of birds as asymptomatic carriers. It was therefore recommended to separate the birds positive with ELISA assay from the birds negative with ELISA assay. In the aforementioned study, almost half of the sera (49\%) came from breeders, retailers or large collections. The main reason for submitting the sera for testing was a screening after a case of PDD. The number of positive birds in such collections ranged between $7.5 \%$ and $52 \%$ (Dorrestein et al. 2012).

In the absence of effective treatments, control must be sought by other methods (Hoppes et al. 2013). There is currently no available vaccine. The disease proved to be immunemediated, and it is possible that a vaccine would be ineffective. Studies are ongoing. Studies focused on ABV shedding patterns suggest that a small number of infected birds are high-level persistent shedders (Hoppes et al. 2013). The control of ABV in aviaries, therefore, requires a multimodal approach. Effective forms of preventive control should be implemented which include isolation of all new, sick, or ABV-positive birds, separation of ELISA or PCR ABV positive birds from a flock, control of traffic, and good sanitation and thorough cleaning of all areas.

This is the first study done in the Czech Republic and Slovakia focused on ABV in parrots. The results revealed that high concentrations of $\mathrm{ABV}$ positive pet birds, as well as $\mathrm{ABV}$ positive parrots from breeding flocks, are present in this region of Europe. A follow-up research study on ABV in avian patients in the Czech Republic and Slovakia is ongoing.

\section{Acknowledgments}

This study was made possible with the financial support of Faculty of Veterinary Medicine (Institucionální výzkum FVL VFU Brno, 2010-2012) and the PDD Research Fund of the Netherlands.

\section{References}

Clark FD 1984: Proventricular dilatation syndrome in large psittacine birds. Avian Diseases 28: 813-815

De Kloet SR, Dorrestein GM 2009: Presence of avian bornavirus RNA and antiavian bornavirus antibodies in apparently healthy macaws. Avian Diseases 53: 568-573

Deb A, Borjal RJ, Bürkle M, Watson R, Hammer S 2008: Evaluation of Avian Paramyxovirus-1 serology and crop biopsy for the diagnosis of proventricular dilatation disease in captive Spix's macaws (Cyanopsitta 
spixii). Proceedings of the $7^{\text {th }}$ Scientific Meeting of the European Association of Zoo and Wildlife Veterinarians (EAZWW) Leipzig, Germany, pp. 239-242

Dorrestein GM, de Kloet SR, Honkavuori KS, Briese T, Tizard I, Bastaansen P, Verhoeven JTP, Sarrafzadeh Zargar D, Verschuren MCM, Lipkin WI 2009: Comparison PCR assays for the detection of avian borna virus in histopathologically proven cases with proventricular dilatation disease in psittacines. Proceedings of the $8^{\text {th }}$ Scientific Meeting of the European Association of Zoo and Wildlife Veterinarians, Beekse Bergen, The Netherlands, pp. 14-18

Dorrestein GM, van BerkelM, van Lit M de Kloet SR 2012: Avian bornavirus: experiences on ELISA and PCR diagnostics related to pathological cases. Proceedings of the $17 \mathrm{t}^{\mathrm{th}}$ DVG TagungüberVogelkrankheiten, München, pp. 135-140

Gancz AY, Kistler AL, Greninger AL, Farnoushi Y, Machani S, Perl S, Berkowitz A, Perez N, Clubb S, Derisi JL, Ganem D, Lublin A 2009: Experimental induction of proventricular dilatation disease in cockatiels (Nymphicus hollandicus) inoculated with brain homogenates containing avian bornavirus 4. Virol J 6: 100-111

Gray P, Hoppes S, Suchodolski P, Mirhosseini N, Payne S, Villanueva I, Shivaprasad HL, Honkavuori KS, Briese T, Reddy SM, Tizard I 2010: Use of avian bornavirus isolates to induce proventricular dilatation disease in conures. Emerg Infect Dis 16: 473-479

Gregory C, Latimer KS, Niagro F, Ritchie BW, Campagnoli RP, Norton TM, Greenacre CB 1994: A review of proventricular dilatation syndrome. J Assoc Avian Vet 8: 69-75

Herzog S, Enderlein D, Heffels-Redmann U, Piepenbring A, Neumann D, Kaleta EF, Müller H, Lierz M, Herden C 2010: Indirect immunofluorescence assay for intra vitam diagnosis of avian bornavirus infection in psittacine birds. J Clin Microbiol 48: 2282-2284

Honkavuori KS, Shivaprasad HL, Williams BL, Quan PL, Horning M, Street C, Palacios G, Hutchison SK, Franca M, Egholm M, Briese T, Lipkin WI 2008: Novel borna virus in psittacine birds with proventricular dilatation disease. Emerg Infect Dis 14: 1883-1886

Hoppes SM, Tizard I, Shivaprasad HL 2013: Avian bornavirus and proventricular dilatation disease: diagnostics, pathology, prevalence, and control.Vet Clin Exot Anim 16: 339-355

Kistler AL, Ganz A, Clubb S, Skewes-Cox P, Fischer K, Sorber K, Chiu CY, Lublin A, Mechani S, Farnoushi Y, Greninger A, Wen CC, Karlene SB, Ganem D, DeRisi JL 2008: Recovery of divergent avian bornaviruses from cases of proventricular dilatation disease: identification of a candidate etiologic agent. Virol J 5: 88-103

Kistler AL, Smith JM, Greninger AL, Derisi JL, Ganem D 2010: Analysis of naturally occuring avian bornavirus infection and transmission during an outbreak of proventricular dilatation disease among captive psittacine birds. J Virol 84: 2176-2179

Piepenbring AK, Enderlein D, Herzog S, Kaleta EF, Heffels-Redmann U, Ressmeyer S, Herden C, Lierz M2012: Pathogenesis of avian bornavirus in experimentally infected cockatiels. Emerg Infect Dis 18: 1-12

Rinder M, Ackermann A, Kempf H, Kaspers B, Korbel R, Staeheli P 2009: Broad tissue and cell tropism of avian bornavirus in parrots with proventricular dilatation disease. J Virol 83: 5401-5407

Rossi G, Ceccherelli R, Crosta L, Dorrestein GM, Mari S, Pesaro S 2011: Anti-ganglioside specific autoantibodies in ganglia of PDD affected parrots. Proceedings of the $11^{\text {th }}$ European AAV conference, $1^{\text {st }}$ Scientific ECZM Meeting, Madrid, pp.177-178

Shivaprasad HL, Ganz AY, Clubb S 2010: Advanced diagnostic approaches and current management of proventricular dilatation disease. Vet Clin Exot Anim 13: 471-494

Villanueva I, Gray P, Mirhosseini N, Payne S, Hoppes S, Honkavuori KS, Briese T, Turner D, Tizard I 2010: The diagnosis of proventricular dilatation disease: Use of a Western blot assay to detect antibodies against avian borna virus. Vet Microbiol 143: 196-201 